\title{
OPEN Diversification of the Balloon bushcrickets (Orthoptera, Hexacentrinae, Aerotegmina) in the East African mountains
}

\author{
Beata Grzywacz $\mathbb{1}^{1 凶}$, Elżbieta Warchałowska-Śliwa $\mathbb{1}^{1}$, Maciej Kociński®1, \\ Klaus-Gerhard Heller ${ }^{2}{ }^{2}$ \& Claudia Hemp ${ }^{3}$
}

East African mountains constitute a network of isolated habitat islands among dry savannah and are thus ideal for studying species diversification processes. This study elucidated the phylogenetic and phylogeographic relationships of all bushcricket species comprising the genus Aerotegmina. Our analysis indicated that large-scale climatic and topographic processes in Africa are likely to have driven speciation in this group, and revealed the cytogenetic traits of the species. Molecular phylogeny supported the monophyly of Aerotegmina and showed that the genus probably originated in the old Eastern Arc Mountains of Tanzania and Kenya. Two lineages were distinguished: small- and large-sized species with geographically distinct habitats. The underlying processes are thought to be eight dispersals, ten vicariance events, and one extinction event linked to repeated fragmentation of the African rainforest. Those processes, in conjunction with habitat change, probably also led to the spatial separation of the species into a northern clade with a diploid number of chromosomes $2 n=32+X 0$ or $2 n=30+n e o-X Y$ and a southern clade with a reduced number of chromosomes $\left(2 n=28+X 0\right.$ or $\left.24+n e o-X_{1} X_{2} Y\right)$. Karyotype analysis suggests that Aerotegmina is currently in the process of speciation.

Tropical montane rainforests are hotspots of species richness and offer diverse habitats for many endemic taxa ${ }^{1,2}$. Such high diversity may be the result of past climate changes and geological events inducing continual increases and decreases in forest areas ${ }^{3,4}$. However, tropical forest biodiversity is under great pressure from human activity and is vanishing rapidly worldwide ${ }^{5}$, also in East Africa ${ }^{6,7}$. The Eastern Arc Mountains in Kenya and Tanzania constitute one of the 17 most threatened hotspots in the world, which are crucial for the conservation of biodiversity and evolutionary heritage ${ }^{2,8-10}$. The Eastern Arc Mountains are a chain of isolated, geologically ancient mountains thought to have been covered by rainforests for millions of years ${ }^{11,12}$. The knowledge of African Orthoptera from that region is far from complete, particularly in terms of taxonomic placement and delimitation across all taxonomic levels. Many of these Orthoptera are flightless, indicating that geological and climatic events could have played a role in the evolution of this group. It has been suggested that the climate changes of the past one to three million years ${ }^{13}$ enhanced speciation in East Africa, as seen in various genera with arrays of morphologically and molecularly closely related species, e.g., in the subtribe Karniellina (subfamily: Conocephalinae ${ }^{14-16}$ ), the genus Peronura (subfamily: Phaneropterinae ${ }^{17}$ ), the genus Parepistaurus (subfamily: Coptacridinae ${ }^{18}$ ), and the family Lentulidae ${ }^{19,20}$. Most inland mountains, such as Mt. Kilimanjaro, adjacent to the geologically old northern branch of the Eastern Arc Mountains, can serve as time markers since their geological age is known. Species endemic to those young volcanoes enable the estimation of speciation processes in closely related species arrays of orthopteran genera present in young and old mountain ranges. The Meru and Kilimanjaro massifs are relatively young with an estimated age of two to three million years ${ }^{21}$, whereas the Eastern Arc Mountains are thought to be over 30 million years old ${ }^{11}$. Importantly, despite the relatively young age of the volcanoes, they harbor a high proportion of endemic orthopteran species, which implies rapid speciation in that region ${ }^{22}$.

The Balloon Bushcricket genus Aerotegmina is a perfect taxon for studying the role of climate and topography in determining patterns of species diversity and distribution. Aerotegmina belongs to the subfamily Hexacentrinae within the family Tettigoniidae and comprises five species so $\mathrm{far}^{23}$. The genus was described by Hemp ${ }^{24}$,

\footnotetext{
${ }^{1}$ Institute of Systematics and Evolution of Animals, Polish Academy of Sciences, Sławkowska 17, 31-016 Kraków, Poland. ${ }^{2}$ Unaffiliated, Magdeburg, Germany. ${ }^{3}$ Department Plant Systematics, University of Bayreuth, Bayreuth, Germany. ${ }^{\circledR}$ email: grzywacz@isez.pan.krakow.pl
} 


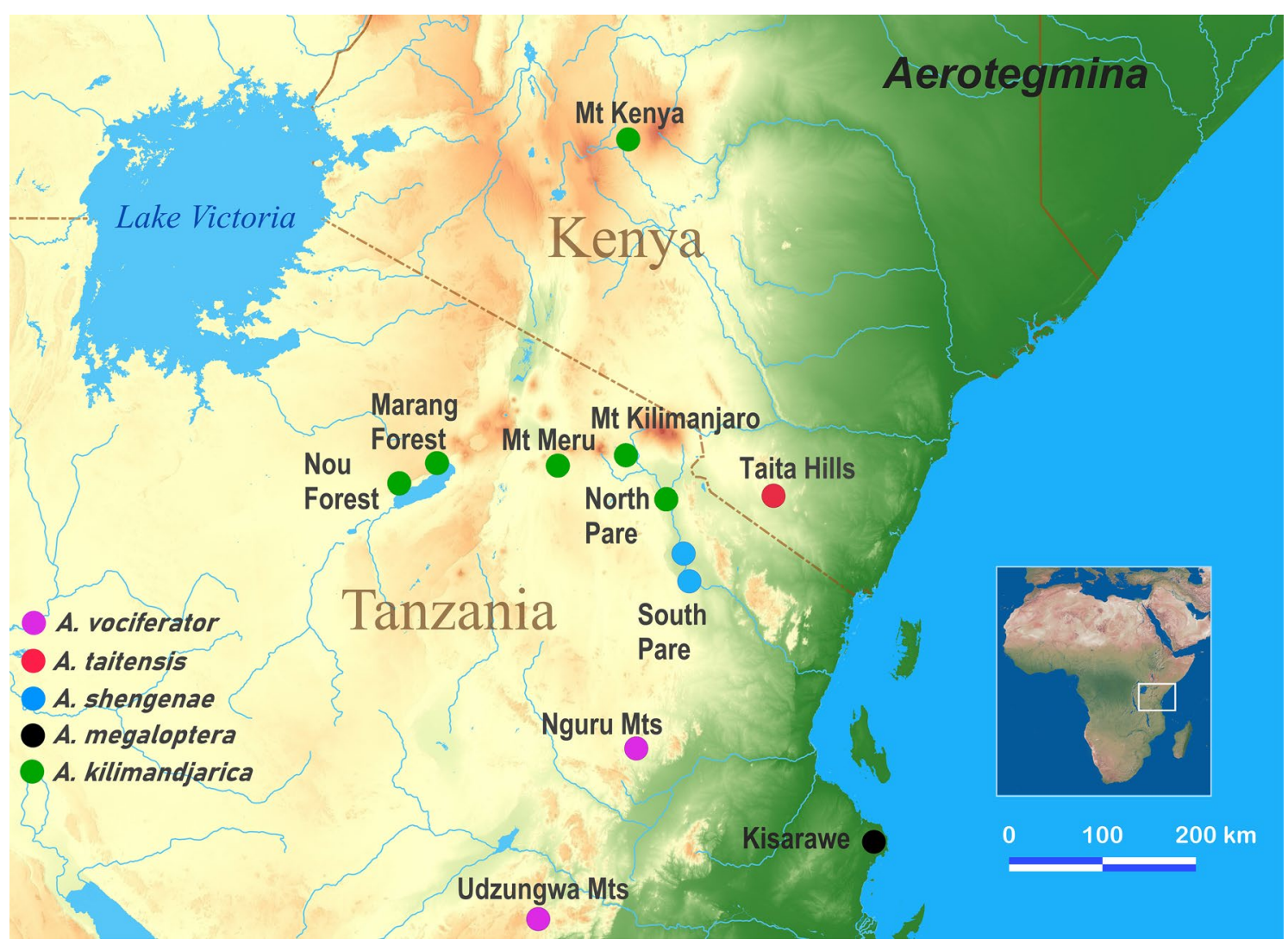

Figure 1. Map of collecting localities of analyzed specimens of Aerotegmina. Created by B. Grzywacz using QGIS 3.6 'Noosa' (http://qgis.osgeo.org) ${ }^{82}$.

with strongly inflated wings used for acoustical communication being its distinctive feature. Bioacoustics of this genus has been extensively studied, the call of some species being among the loudest known in insects ${ }^{25}$. Two groups of Aerotegmina species can be distinguished by their small or large body size as well as their extremely divergent song pattern ${ }^{25}$. According to Hemp ${ }^{26}$, Aerotegmina probably originated in the Eastern Arc Mountains. All of its species are canopy dwellers found in lowland to montane forests along the coast, in both old and young East African mountains. To date, only two Aerotegmina species (A. kilimandjarica and A. shengenae) have been studied cytogenetically, with the male diploid chromosome number being $2 \mathrm{n}=32+\mathrm{X} 0$ in A. kilimandjarica and $2 \mathrm{n}=26+\mathrm{X} 0$ in A. shengenae ${ }^{27}$.

At present, the molecular phylogeny of Aerotegmina is poorly known. The relationship of the genus was proposed by Hemp et al. ${ }^{27}$ based on morphological, bioacoustical, and chromosomal evidence. In this study, we provide comprehensive information on the molecular phylogeny and cytogenetics of this genus and discuss the ecological processes leading to species diversification and the current biogeography of the group. First, the taxonomic status of Aerotegmina species is assessed using genetic samples from across the range of the genus. Second, the molecular clock approach is used to investigate whether the timing of divergences within this clade corresponds with specific geological and climatic events in Africa. Phylogeographic tools were used to determine if speciation was affected by dispersal, vicariance, and extinction events. Finally, the cytogenetic characters of each species are provided.

\section{Material and methods}

Taxon sampling. A total of 64 individuals from five Aerotegmina species, three individuals from two Hexacentrinae taxa (two individuals-Hexacentrus sp. and one-Nepheliphila raptor Hugel, 2010) and two individuals from two Meconematinae taxa (Breviphisis sp. and Longiphisis sp.) were collected in the field (Table S1, Fig. 1). Six outgroup Meconematinae taxa were selected for this study.

DNA extraction, amplification, and sequencing. DNA was extracted from the legs of specimens using the NucleoSpin tissue kit (Macherey-Nagel, Germany) following the manufacturer's protocol. Three molecular markers were used for reconstructing the interspecific relationships of Aerotegmina: cytochrome c oxidase subunit I (COI), 16S ribosomal RNA (16S), and histone 3 (H3), which have proved useful in previous studies of closely related groups of East African bushcrickets (e.g., ${ }^{14-16,28,29}$ ). PCR amplification and cycle sequencing of the three gene fragments were carried out with the following primers: LCO and HCO for COI ${ }^{30}, 16 \mathrm{a}$ and $16 \mathrm{~b}$ for $16 \mathrm{~S}^{31}$, and $\mathrm{H} 3 \mathrm{fwd}$ and $\mathrm{H} 3 \mathrm{rev}$ for $\mathrm{H}^{32}$. The amplification reaction was performed in a $20 \mu \mathrm{L}$ reaction volume consisting of $2.0 \mu \mathrm{L}$ of $10 \times \mathrm{PCR}$ buffer, $25 \mathrm{mM}$ of $\mathrm{MgCl}_{2}, 10 \mathrm{mM}$ of dNTP mixture, $10 \mu \mathrm{M}$ of forward 
and reverse primers, 1-3 $\mu \mathrm{L}$ of genomic DNA, and 5U/ $\mu \mathrm{L}$ of Gold Taq DNA polymerase (Syngen, Poland), and sterile deionized water. To amplify COI, the following PCR protocol was used: 36 cycles at $94{ }^{\circ} \mathrm{C}$ for $1 \mathrm{~min}$, at $48^{\circ} \mathrm{C}$ for $1 \mathrm{~min}$, and at $72^{\circ} \mathrm{C}$ for $2 \mathrm{~min}$, with a final extension at $72^{\circ} \mathrm{C}$ for $7 \mathrm{~min}$. The PCR conditions for the $16 \mathrm{~S}$ gene were as follows: $38 \mathrm{cycles}$ at $94^{\circ} \mathrm{C}$ for $45 \mathrm{~s}$, at $48^{\circ} \mathrm{C}$ for $45 \mathrm{~s}$, and at $72{ }^{\circ} \mathrm{C}$ for $80 \mathrm{~s}$, with a final extension at $72^{\circ} \mathrm{C}$ for $1 \mathrm{~min}$. In the case of $\mathrm{H} 3$, the PCR procedure consisted of $30 \mathrm{cycles}$ at $94^{\circ} \mathrm{C}$ for $15 \mathrm{~s}$, at $55^{\circ} \mathrm{C}$ for $15 \mathrm{~s}$, and $72{ }^{\circ} \mathrm{C}$ for $30 \mathrm{~s}$, with a final extension at $72^{\circ} \mathrm{C}$ for $1 \mathrm{~min}$. All PCR products were purified using Exo-BAP Mix (EURx, Poland, following the standard protocol) and were sequenced using the BrilliantDye v3.1 Terminator Cycle Sequencing Kit (NimaGen, Netherlands), and ABI 3730XL sequencer. The sequences generated for this study were deposited in the GenBank database under the accession numbers given in Table S1. The sequences were checked and edited using CodonCode Aligner (CodonCode Corporation). The DNA sequences of Amytta kilimandjarica, A. meruensis, A. merumontana, and A. olindo were selected from GenBank to be included as an outgroup in the dataset. For all genes, separate alignments were conducted using ClustalX ${ }^{33}$. Sequences were checked for protein-coding frame shifts to detect pseudogenes using MEGA $\mathrm{X}^{34}$ and compared with sequences from GenBank through a Blast search. The potential saturation of the nucleotide substitution was checked for all markers separately and for two separate partitions of COI (with codon positions $1+2$ and codon position 3). Saturation was examined through the substitution saturation test ${ }^{35}$ implemented in $\mathrm{DAMBE}^{36}$. The partition homogeneity test ${ }^{37}$ in PAUP ${ }^{38}$ with 1000 replicates was used to determine whether all regions (COI, 16S, H3) could be combined in a unique data matrix.

Phylogenetic analyses. Two methods were used to establish phylogenetic relationships: Bayesian inference (BI) and maximum likelihood (ML). A model of sequence evolution was selected with MrModeltest software $^{39}$. MrBayes ${ }^{40}$ was used to obtain a BI tree. The symmetrical gamma distribution model (SYM $\left.+\mathrm{G}\right)$ was the best-fit for the COI, 16S and H3 considered separately. Posterior probabilities were based on two independent Markov chain Monte Carlo (MCMC) runs, each composed of four chains (three heated and one cold). Markov chains were run for 6 million generations with sampling every 100 generations. The default $25 \%$ burn-in was applied before constructing the majority-rule consensus tree. The convergence of analyses was validated by evaluating likelihood values using $\operatorname{Tracer}^{41}$. ML estimates of phylogeny were implemented in IQ-TREE ${ }^{42}$.

Divergence time estimation and biogeographic analysis. To estimate the divergence time of each clade without any molecular clock constraint, a Bayesian approach with MCMC integration was used to date the most recent common ancestor using Beast software ${ }^{43}$. The analysis was run for 20 million generations with sampling every 1000 generations and a 10\% burn-in. A Yule branching process with a lognormal relaxed clock for estimating the posterior probability density of divergence time was implemented. Convergence to the stationary distribution and the effective sample size of the model parameters were checked using Tracer. Maximum clade credibility trees were generated with TreeAnnotator ${ }^{43}$. The tree was calibrated using two calibration points from Mugleston et al. ${ }^{44}$ : an Aerotegmina-Hexacentrus split 37.5 Mya and Aerotegmina-Meconematinae split 90 Mya, with a normal distribution centered on 37.5 Mya and 90 Mya, respectively, at one standard deviation to reflect the uncertainty associated with the original estimate. Additionally, for the two on Mts Kilimanjaro and Meru endemic meconematine sister pairs Amytta kilimandjarica and A. merumontana and A. olindo and A. meruensis the molecular clock was calibrated using the event of volcanism representing the origin of Mt. Kilimanjaro with a normal distribution centered on $1.75 \mathrm{Mya}^{29}$.

The maximum clade credibility tree and distribution file were uploaded to show the biogeographic reconstruction obtained by statistical dispersal-vicariance analysis $\left(\right.$ S-DIVA ${ }^{45}$ ) implemented in RASP ${ }^{46}$. The number of maximum ancestral areas was set to 4 , whereas trees and a condensed tree were generated by Beast. S-DIVA was conducted with the default settings. Eleven biogeographical regions related to the sampled sites of Aerotegmina were defined: Mt. Kilimanjaro, Marang Forest, Mt. Kenya, Mt. Meru, Nou Forest, Taita Hills, North Pare Mountains, South Pare Mountains, Kazimzumbwi Forest Reserve (Kisarawe), Nguru Mountains, and Udzungwa Mountains.

Cytotaxonomic analyses. The study material consisted of Aerotegmina kilimandjarica (new data, three males: HE6, HE9, HE43 and seven described in ${ }^{27}$ : $\mathrm{CH} 6825, \mathrm{CH} 6827, \mathrm{CH} 6850-54$ ), A. shengenae (new data, five males: CH8676, CH8677, CH8317, CH8318, CH8320, HE127, HE128, HE131 and one described in ${ }^{27}$ : $\left.\mathrm{CH} 7268\right)$, A. taitensis (three males: HE119, HE120, HE122), A. vociferator (one male: HE123), and A. megaloptera (five males: HE39, HE40, HE43, CH8026, CH8309). Chromosome preparations were obtained from gonads and hepatic caeca. Testes and somatic body parts were incubated in a hypotonic solution ( $0.9 \%$ sodium citrate), fixed in ethanol:acetic acid $(3: 1)$ and stored at $2{ }^{\circ} \mathrm{C}$ until use. The fixed material was squashed in $45 \%$ acetic acid. Coverslips were removed by the dry ice procedure and then the preparations were air-dried. Constitutive heterochromatin was revealed by the C-banding technique as described by Sumner ${ }^{47}$. Chromosomes were examined using a Nikon Eclipse 400 microscope with a CCD DS-U1 camera and NIS-Elements BR2, and the images were processed and arranged with Adobe Photoshop. For each individual, at least three spermatogonial mitotic metaphases and 15 meiotic divisions in males (except $A$. vociferator) were examined.

To estimate the ancestral character states for the number of chromosomes we used a continuous-time Markov chain model implemented in "phytools" ${ }^{48} \mathrm{R}$ package ${ }^{49} .500$ trees were simulated to obtain state probability. It was visualized on the modified Beast chronogram. 


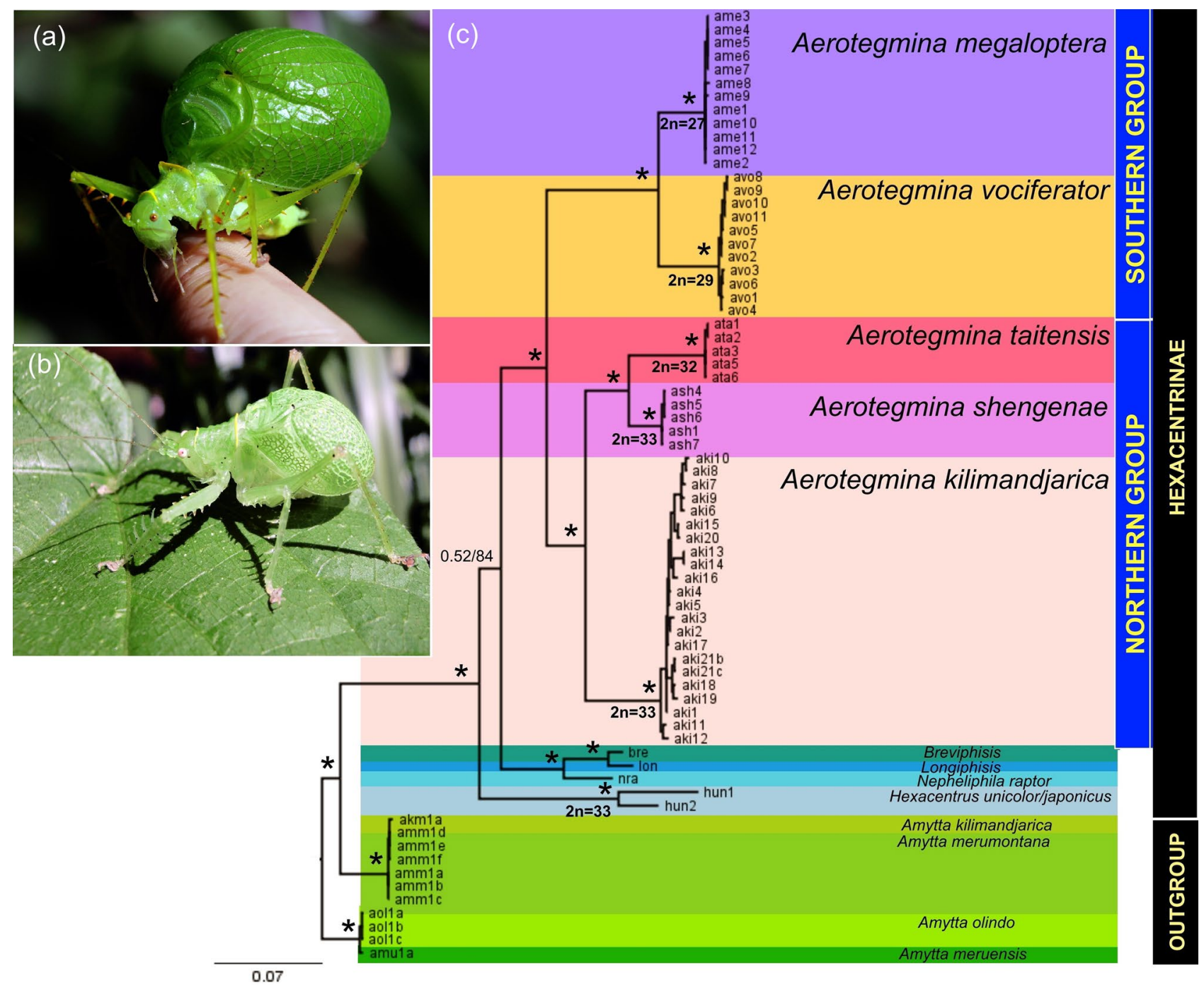

Figure 2. Aerotegmina megaloptera (a), A. shengenae (b), photo C. Hemp. Bayesian inference tree from a dataset including COI, 16S, and H3 sequences of Hexacentrinae genera (c). Bayesian (BI) and Maximum likelihood (ML) topologies were consistent, so only one tree is shown. Values at nodes correspond to posterior probability/bootstrap support; ${ }^{\star}$ designates $\leq 0.99$ and $95 \%$ values for BI and ML, respectively. Diploid chromosome numbers for Aerotegmina species are plotted on the phylogenetic tree. Scale bar: number of substitutions per nucleotide position. OUT—outgroup, HEXA-Hexacentrinae.

\section{Results}

Phylogeny, dating, and biogeography. Samples were successfully sequenced for all markers. A total of 1500 positions were aligned within the dataset. The results of the substitution test for each gene alignment are summarized in Table 1. Calculated $P$-values were significant for all gene alignments and Iss (index of substitution saturation) values were lower than Iss.c (critical index of substitution saturation) in all cases. No saturation of the phylogenetic signal was observed for the COI, $16 \mathrm{~S}$ and $\mathrm{H} 3$ dataset.

The topologies obtained from BI and ML analyses for the combined dataset were similar. Figure 2 shows the $\mathrm{BI}$ consensus tree based on combined COI, 16S, and H3 data. All specimens of each Aerotegmina species formed a monophyletic group. The Aerotegmina species were split into two major lineages showing morphological differences. The northern group consisted of the three small-sized taxa: the widespread $A$. kilimandjarica being the sister group to the two endemic species A. shengenae from the South Pare Mountains in Tanzania and $A$. taitensis from the Taita Hills in Kenya. The southern group consisted of two large-sized species: A. vociferator from the Nguru and Udzungwa populations clustered together and A. megaloptera from coastal Tanzania. Small molecular differences at the population level could be detected between A. kilimandjarica specimens from Mt. Kilimanjaro and the North Pare Mountains, despite this they formed one subclade within the northern group.

The topology resulting from the molecular clock was similar to the Bayesian tree (Fig. 3). Based on the molecular clock analysis and a priori calibration, the divergence of the small- and large-sized species was dated at ca. 2.8 Mya (1.81-4.04 Mya, 95\% confidence interval). The major clades of the small-sized species are likely to have diverged ca. 1.98 Mya (1.16-2.89 Mya, 95\% confidence interval) and those of the large-sized species ca. 


\begin{tabular}{|l|l|l|l|l|l|}
\hline Dataset & ISS & ISS.c S & $\boldsymbol{P}$ & ISS.c A & $\boldsymbol{P}$ \\
\hline COI $(1+2)$ & 0.0969 & 0.6953 & 0 & 0.3978 & 0 \\
\hline COI $(3)$ & 0.3802 & 0.6368 & 0 & 0.3601 & 0.4996 \\
\hline 16S & 0.5401 & 0.7312 & 0.0001 & 0.4912 & 0 \\
\hline H3 & 0.0777 & 0.7204 & 0 & 0.5955 & 0 \\
\hline
\end{tabular}

Table 1. Results of the substitution saturation tests performed in DAMBE.

1.19 Mya (0.19-2.24 Mya, 95\% confidence interval). Divergence events among the two main species lineages were placed in the late Pliocene (ca. 5.33-2.6 Mya).

The biogeographic scenario indicates that the current distribution pattern of Aerotegmina results from eight dispersals, ten vicariance, and one extinction events (Fig. 3). The main divergence of Aerotegmina was dated to the late Pliocene ( ca 2.8 Mya). The S-Diva analysis on the Beast tree identified Kazimzumbwi Forest Reserve (Kisarawe), Mt. Meru, the Taita Hills and the Udzungwa Mountains, after four dispersals, one extinction and one vicariance as ancestral area for Aerotegmina species. For the southern group (large-sized species: A. megaloptera, A. vociferator) of Aerotegmina the ancestral areas were Kazimzumbwi Forest Reserve (Kisarawe), the Udzungwa Mountains and the Nguru Mountains after one vicariance. Finally, A. megaloptera occupied Kazimzumbwi Forest Reserve (Kisarawe) while A. vociferator occurred in the Udzungwa Mountains and the Nguru Mountains. For the northern group (small-sized species: A. shengenae, A. taitensis, A. kilimandjarica) of Aerotegmina the ancestral areas were the South Pare, the Taita Hills, Mt. Kilimanjaro and Marang Forest after a vicariance and two dispersals. Aerotegmina shengenae dispersed from the ancestral area to the South Pare Mountains whereas A. taitensis to the Taita Hills. The S-DIVA analysis for the A. kilimandjarica species group found one vicariance event and two dispersals, leading to the current distribution pattern of this species, today occurring in montane forests of the Manyara Escarpment (Nou Forest, Marang Forest), on Mt. Kilimanjaro and on Mt. Kenya.

Chromosomes. A comparison of the karyotypes of five Aerotegmina species revealed differences in the number of chromosomes (2n), the chromosome morphology (including X and Y chromosomes), the fundamental number of chromosome arms (FN), the sex chromosome system, and C-banding. The examined Aerotegmina males had 33 to 27 chromosomes and one of three sex determination systems: X0, neo-XY, or neo- $\mathrm{X}_{1} \mathrm{X}_{2} \mathrm{Y}$.

The standard karyotypes of Aerotegmina kilimandjarica and A. shengenae (both new data) were characterized by a chromosome number of $2 \mathrm{n}=32+\mathrm{X} 0, \mathrm{FN}=33$ in males. The chromosomes were acrocentric, consisting of one long and 15 medium-sized or short pairs gradually decreasing in size, as well as an X chromosome, the largest element in the set. In both species, one medium-sized autosome pair (probably the fifth) was heterochromatinized, demonstrating in some individuals megameric characteristics. In the $\mathrm{X}$ chromosome, thick paracentromeric C-bands and thin telomeric ones were found in both species. Thin or thick paracentromeric and thin telomeric C-positive heterochromatin blocks occurred in most autosomes in A. kilimandjarica (new data $\operatorname{and}^{27}$ ), whereas in A. shengenae the second pair had thick C-bands (Fig. 4a-d). At diakinesis/metaphase I cells with this chromosome/bivalent number were clearly visible (Fig. $4 \mathrm{~b}$, d, respectively).

A. taitensis males had a chromosome number of $2 \mathrm{n}=30+$ neo-XY, $\mathrm{FN}=32$. Two long and thirteen mediumsized/short autosome pairs, a neo-X and neo-Y chromosome were acrocentric. This species had thin paracentromeric C-bands in most autosomes, except for the first and third pairs with a thick C-heterochromatin block. Additionally, a very weak interstitial C-band occurred in the second pair and a thick distal C-block in the fourth pair. The neo-X was the largest chromosome in the set, with thick paracentromeric and minute telomeric C-positive blocks, whereas the medium-sized neo-Y chromosome was strongly heterochromatinized (Fig. 4e, f, h). During pachytene, the sex chromosomes formed a ring or a loop (Fig. 4g), whereas in diakinesis/metaphase I the neo-X and neo-Y chromosomes were joined near both distal parts (Fig. 4f). At metaphase II there were 16 chromosomes, including a neo-X or neo-Y (Fig. 4h).

In A. vociferator (a single male with somatic mitosis), the chromosome number was reduced to $2 \mathrm{n}=28+\mathrm{X} 0$, $\mathrm{FN}=31$. Fourteen pairs of autosomes, one large metacentric and thirteen medium-sized/short acrocentric, were arranged into two groups; thin C-bands were located in the paracentromeric region in most autosomes, except for the third or fourth pair (megameric) with strong thick C-bands occupying most of the chromosomes. The $\mathrm{X}$ chromosome was the second element of the set with thick paracentromeric and minute telomeric $\mathrm{C}$ heterochromatin bands (Fig. 5a).

The lowest chromosome number, $2 \mathrm{n}=24+$ neo- $\mathrm{X}_{1} \mathrm{X}_{2} \mathrm{Y}, \mathrm{FN}=31$ was found in A. megaloptera. This species had one large metacentric and eleven acrocentric autosome pairs. Heterochromatin formed thin C-positive paracentromeric bands in most of the chromosomes; the medium-sized (probably third) chromosome pair could be considered megameric. A submetacentric neo- $\mathrm{X}_{1}$ was the second element in the karyotype, whereas an acrocentric neo- $\mathrm{X}_{2}$ was similar in length to the medium-sized autosomes. The submetacentric neo- $\mathrm{Y}$ was about two times as large as the neo- $\mathrm{X}_{2}$ (Fig. 5b). During the early prophase (zygotene-pachytene-diplotene), the neo- $\mathrm{X}_{1}$ was positively heteropycnotic (Fig. 5c). At diakinesis, the sex chromosomes were generally connected by a single terminal chiasma or end-to-end association. During metaphase $\mathrm{I}$, the neo- $\mathrm{X}_{1}$ was terminally associated with the "left" arm of the metacentric $Y$, whereas the acrocentric neo- $\mathrm{X}_{2}$ was associated with the "right" arm of the neo-Y (Fig. 5d). After anaphase I, two types of metaphase II complements were formed, with 14 chromosomes $\left(12+\right.$ neo- $\mathrm{X}_{1}$, neo- $\left.\mathrm{X}_{2}\right)$ and 13 chromosomes $(12+$ neo-Y), respectively (Fig. 5e). Thick paracentromeric C-bands 


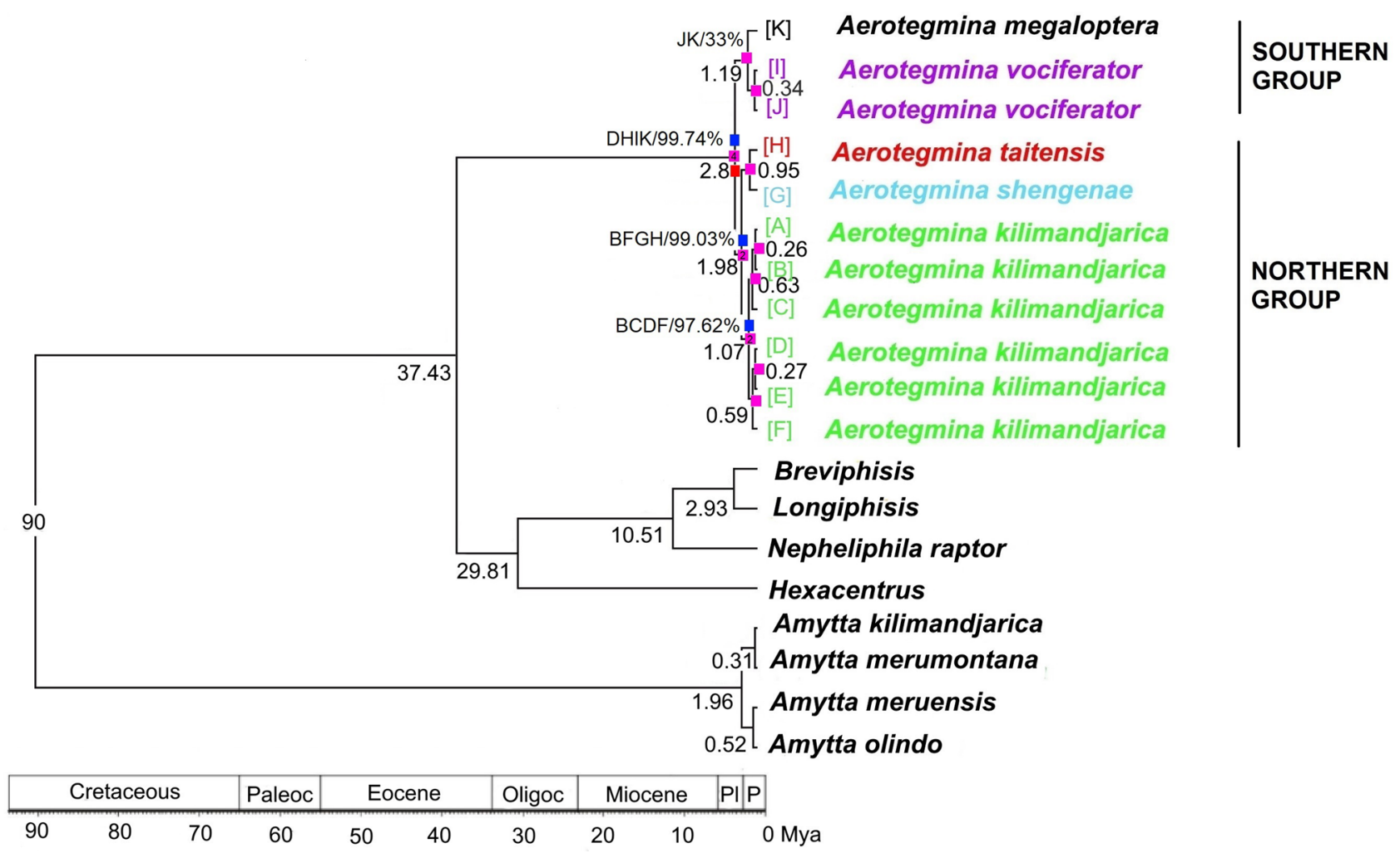

Figure 3. Reconstructed geographic ranges and dated phylogeny of Aerotegmina obtained through phylogenetic analysis using Beast software with a relaxed molecular clock model (Beast tree is given). The values indicated under the branches represent the mean ages of lineage divergence; acronyms on the nodes and at the tip labels indicate geographic areas: [A]-North Pare Mountains, [B]-Marang Forest, $[\mathrm{C}]-\mathrm{Mt}$. Kenya, [D]—Mt. Meru, [E]—Nou Forest, [F]—Mt. Kilimanjaro, [G]—South Pare Mountains, [H]—Taita Hills, [I]-Udzungwa Mountains, [J]-Nguru Mountains, [K]-Kazimzumbwi Forest Reserve (Kisarawe); the values above branches support the predicted distribution. The different colour squares on the branches close to the nodes represent different events: pink—vicariance, navy blue-dispersal and red-extinction; digit inside the square means how many events were at the node (showing only values greater than 1). Mya-million years ago, Paleoc_-Paleocene, Oligoc-Oligocene, $\mathrm{Pl}$-Pliocene and P-Pleistocene.

were found on both bi-armed neo- $\mathrm{X}_{1}$ and neo-Y, whereas a thin C-positive band was observed in the neo- $\mathrm{X}_{2}$ sex chromosome. Additionally, a minute telomeric C-block was observed in the neo- $\mathrm{X}_{1}$ (Fig. 5b).

The ancestral character states analysis (Fig. 6) revealed the ancestor of Aerotegmina most likely had a chromosome number $2 \mathrm{n}=33$ chromosomes.

\section{Discussion}

The presented molecular analyses confirmed the monophyly of the genus Aerotegmina and a species diversification timeline was established. Speciation coincided with the climatic and geological phenomena leading to dispersal, which resulted in a clear spatial phylogenetic pattern. Moreover, phylogeny was found to be associated with differences in body size and in the number and structure of chromosomes.

Two morphological groups of Aerotegmina. This study is the first comprehensive molecular analysis of Aerotegmina. All previous works were based on morphological, bioacoustical, or cytogenetic data ${ }^{25,27}$. The present findings showed that Aerotegmina is monophyletic within Hexacentrinae (posterior probability support, $\mathrm{PP}=1.0$; bootstrap support, $\mathrm{BP}=100$ ) and is a sister clade to Breviphisis, Longiphisis, and Nepheliphila (Fig. 2). The morphology of the species of northern Tanzania and Kenya (A. kilimandjarica, A. shengenae, A. taitensis) and southern Tanzania (A. megloptera and A. vociferator) showed differences, especially in body size. The northern group consisted of two morphologically very closely related species, A. shengenae and A. taitensis, endemic to the South Pare Mountains and the Taita Hills, respectively, belonging to the ancient Eastern Arc Mountains. A similar pattern of geographically separated species is also seen in various other genera of flightless Orthoptera, e.g., Peronura ${ }^{50}$, Rhainopomma ${ }^{19,51}$, Parepistaurus $^{52}$, and Melanoscirtes ${ }^{53}$. Specimens from different A. kilimandjarica populations formed a sister group to the sister pair of $A$. taitensis and A. shengenae. These results agree with previous preliminary molecular studies ${ }^{54}$. The present data do not confirm the assumption that A. shengenae is the most basal species of the group, as suggested in previous studies ${ }^{27,55}$ based on morphology (small, incompletely closed acoustic chamber) and acoustics (less loud than A. kilimandjarica). The southern group, formed by the large-sized species $A$. megaloptera and A. vociferator represented a sister group to all small- 

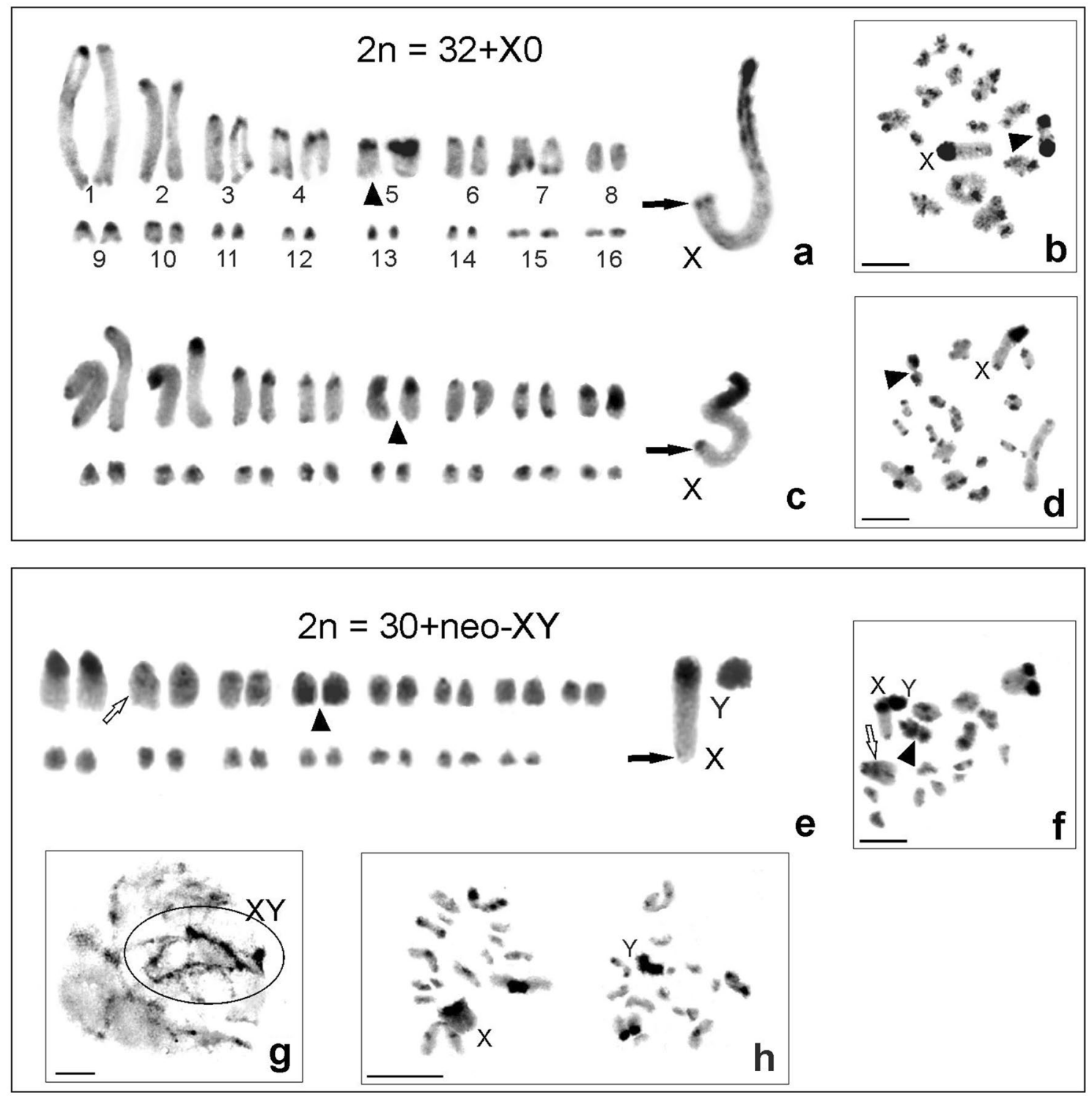

Figure 4. Heterochromatin C-banding at karyograms arranged from mitotic metaphase (a, c, e), pachytene (g), diakinesis/metaphase I (b, d, f), and metaphase II (h) for male chromosome complements in Aerotegmina kilimandjarica $(\mathbf{a}, \mathbf{b})$ and $A$. shengenae $(\mathbf{c}, \mathbf{d}) 2 \mathrm{n}=32+\mathrm{X} 0$ and $A$. taitensis $2 \mathrm{n}=30+$ neo-XY $(\mathbf{e}-\mathbf{h})$. X chromosome with thick paracentromeric and telomeric C-bands (black arrows) (a, c, e); medium-sized pairs exhibit thick paracentromeric heterochromatin (arrowheads) $(\mathbf{a}-\mathbf{f})$; marked by white arrow weak interstitial C-band in second pair $(\mathbf{e}, \mathbf{f})$. In the neo-XY system, sex chromosomes form a ring $(\mathbf{g})$, both acrocentric neo-X and neo-Y are connected by telomeric segments (f); metaphase II with 16 chromosomes $(15+$ neo-X and $15+$ neo-Y) (h). Scale bar $=10 \mu \mathrm{m}$.

sized species of northern Tanzania and southern Kenya, which is consistent with the morphological differences between these two groups.

Our findings stand in opposition to the current taxonomic status of the genera Breviphisis and Longiphisis ${ }^{56}$. Probably, the two genera should be transferred from Meconematinae to the subfamily Hexacentrinae, in contrast to the concept of Gorochov ${ }^{57}$ but further studies are required to confirm their taxonomic position.

Fragmentation of forest cover boosting speciation of Aerotegmina. The aridification-induced fragmentation of the forest cover isolated the ancestors of Aerotegmina probably in the old forests of the Eastern Arc range during the Eocene. With the onset of the East African aridification (33-20 Mya), the forests of the Eastern Arc Mountains were isolated, which would explain the high endemicity of the area (e.g. ${ }^{8,58-60}$ ). In their studies of the family Annonaceae, Couvreur et al. ${ }^{61}$ found that all East African taxa diversified prior to the Pleistocene and that their origins coincide with known periods of aridification and geological activity in Africa which repeatedly isolated the Guinea-Congolian rainforest from the East African one. A major split in Hexacentrinae on the genus level was observed in the Eocene at 37.43 Mya. The results of S-DIVA revealed that Aerotegmina most recent common ancestor (2.8 Mya) was already present in a wide range covering the Taita Hills, Kazim- 

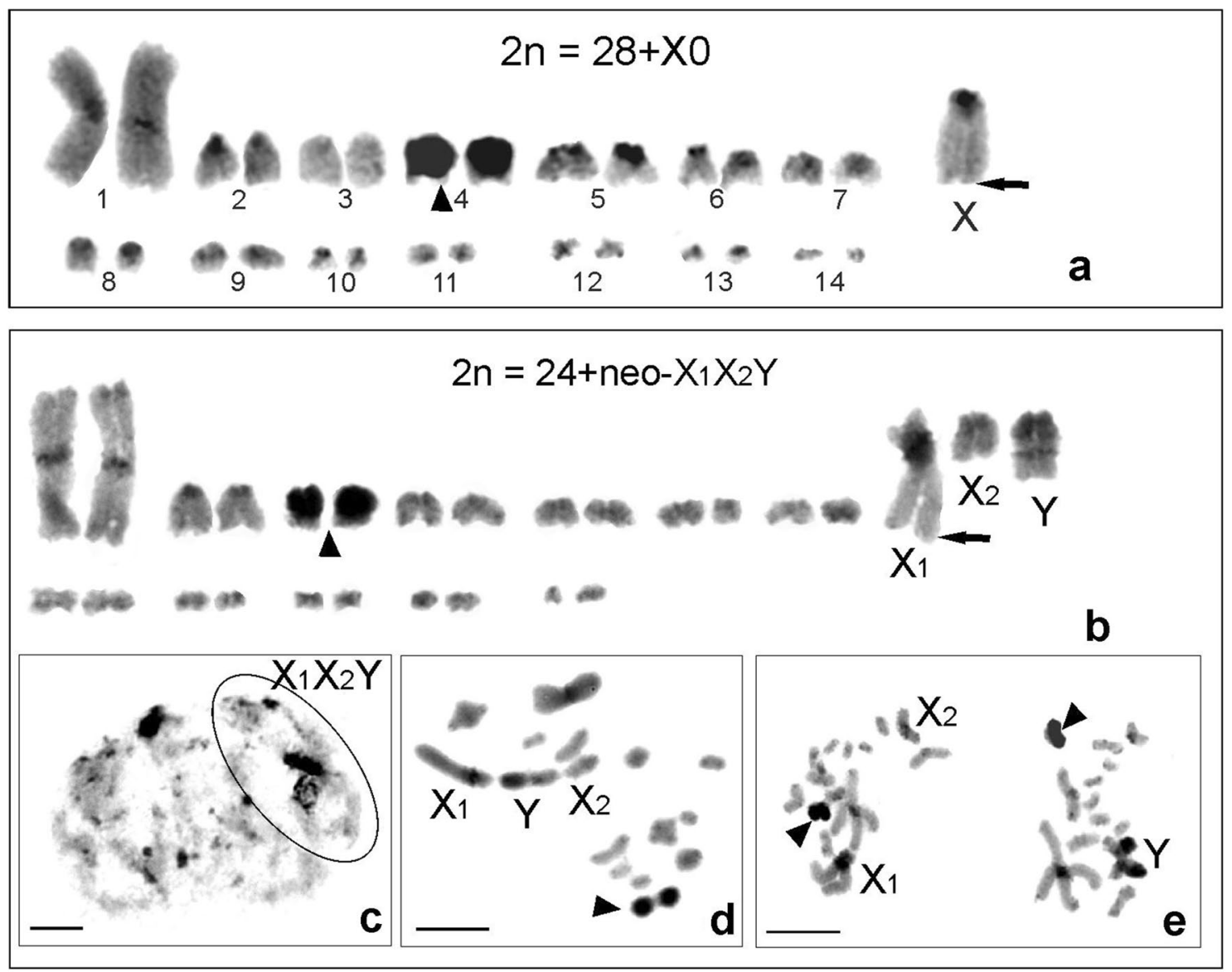

Figure 5. C-banded karyograms arranged from mitotic metaphases of Aerotegmina vociferator $2 \mathrm{n}=28+\mathrm{X} 0$ (a) and A. megaloptera $2 \mathrm{n}=24+$ neo- $\mathrm{X}_{1} \mathrm{X}_{2} \mathrm{Y}(\mathbf{b}-\mathbf{e})$; medium-sized megameric pair (arrowheads) (a, b, d, e). The neo- $\mathrm{X}_{1} \mathrm{X}_{2} \mathrm{Y}$ system: pachytene with positively heteropycnotic $\mathrm{X}_{1}(\mathbf{c})$, terminally associated sex trivalent $(\mathbf{d})$, and metaphase II with two types of secondary spermatocytes with 14 chromosomes $\left(12+\right.$ neo- $\mathrm{X}_{1}$ and neo- $\left.\mathrm{X}_{2}\right)$ and 13 chromosomes $(12+$ neo-Y $)(\mathbf{e})$. Scale bar $=10 \mu \mathrm{m}$.

zumbwi Forest Reserve (Kisarawe), Mt. Meru and the Udzungwa Mountains but not the South Pare Mountains as previously suggested ${ }^{27}$. It is difficult to infer the biogeographic histories of Aerotegmina but probably the old Eastern Arc Mountains of Tanzania and Kenya were the habitat of the ancestors of this genus. Interesting is that the Taita Hills and the South Pare Mountains share a pair of closely related endemic species (A. shengenae and A. taitensis) but it is unclear which species is the basal one. The split of the small-sized Aerotegmina species from the large-sized species occurred in the Pliocene around 2.8 Mya. It overlapped with a global climatic shift which resulted in a major increase of grassland habitats and consequently a change in species composition ${ }^{62,63}$. Humid periods reconnecting forest cover triggered a dispersal event leading to the separation of the northern small-sized species and the large-sized species distributed further south which changed their habitat during their evolution. All small-sized Aerotegmina species are restricted to montane forests in the Eastern Arc Mountains (A. shengenae, A. taitensis, A. kilimandjarica) while a habitat change is obvious for the large-sized species: $A$. vociferator now occurs in montane to submontane forests in the Udzungwa and Nguru Mountains, while $A$. megaloptera is found in lowland wet forests. Also the speciation of Lentulidae (Orthoptera) coincides with the fragmentation of the African rainforests, and subsequently the East African lentulids diversified rapidly in the Eastern Arc Mountains along with the aridification of large parts of Africa and strong geological activity ${ }^{19,20}$.

It was believed that $A$. kilimandjarica was endemic to Mt. Kilimanjaro because it is an immobile flightless dweller of the canopy layer of submontane and montane forest ${ }^{24}$. However, more intensive sampling revealed that A. kilimandjarica is the only species widespread on both young and old mountains in the area, being distributed from the North Pare Mountains, across Mt. Kilimanjaro, Mt. Meru, and the Ngorongoro area to central Kenya (Mt. Sabuk, Mt. Kenya). In this study mainly specimens from the North Pare Mountains, Mt. Kilimanjaro, and only single individuals from Mt. Kenya, Mt. Meru and the Nou and Marang Forest Reserves on the Manyara Escarpment were analyzed. Small molecular differences were detected between the investigated populations of these areas, which is in line with Schultz ${ }^{54}$, suggesting present isolation of these populations from each other and a recent dispersal of this species in East Africa ${ }^{27}$. A specimen from the Marang Forest Reserve, adjacent to the Nou Forest Reserve, clustered with the North Pare and Kilimanjaro individuals. The current genetic differences could result from fragmentation of a formerly widespread species. Climatic fluctuations could affect the connectivity among A. kilimandjarica populations both increasing and preventing migration of individuals. Migration events 


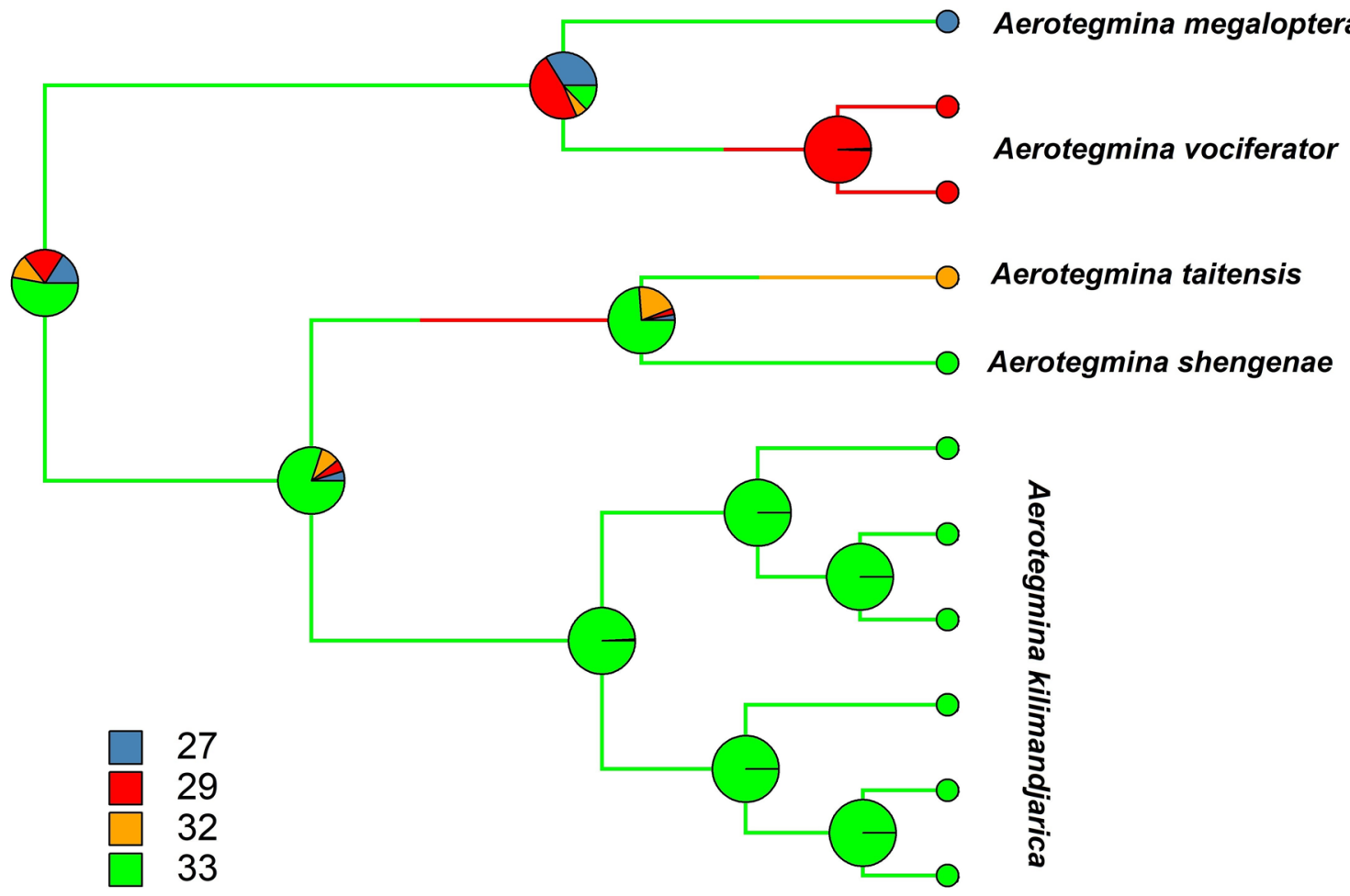

Figure 6. The ancestral character states for number of chromosomes mapped on the modified Aerotegmina Beast chronogram. The different colour branches present different chromosome numbers (explained by squares in the left corner). Circles represent the posterior probability of being in each state across all the edges and nodes of the tree.

occurred during humid and cooler times when the montane forest zones were reconnected. It is assumed that migration was not regulated by accidental shifts, e.g. wind or birds. More analyses on the faster evolving genes should be undertaken to clarify the more recent spread of A. kilimandjarica. It is likely that A. kilimandjarica evolved in the geologically old Eastern Arc Mountains and spread from there once Mt. Kilimanjaro was formed about 2 Mya, opening montane forests corridors further west (Mt. Meru, Ngorongoro area) and north (up to Mt. Kenya). Further analyses of additional populations of $A$. kilimandjarica would elucidate whether the ice age cycles creating montane forest corridors triggered a dispersal of that species and would enable a deeper understanding of the complex relationships between a changing climate, forests and A. kilimandjarica occurrence.

The evolutionary history of Aerotegmina under a cytogenetic perspective. The use of molecular phylogenetics to analyse the karyotype evolution is an objective tool to determine the direction of changes that cause chromosome variation ${ }^{64,65}$. A comparison of the chromosomes of the five studied Aerotegmina species (including previous data ${ }^{27}$ ) revealed differences between their karyotypes. The chromosomal complement was very variable in both the diploid number in males and the sex determination system $(2 \mathrm{n}=32+\mathrm{X} 0,2 \mathrm{n}=30+$ neo$\mathrm{XY}, 2 \mathrm{n}=28+\mathrm{X} 0,2 \mathrm{n}=24+$ neo- $\left.\mathrm{X}_{1} \mathrm{X}_{2} \mathrm{Y}\right)$. The basal chromosome number may be directly related to the chromosomal variability of Aerotegmina and its two molecularly and morphologically distinguished groups. In the northern group, the ancestral chromosome number and sex determination mechanism, $2 \mathrm{n}=32+\mathrm{X} 0(\mathrm{FN}=33)$ found in $A$. kilimandjarica ${ }^{27}$ and $A$. shengenae was reduced to $2 \mathrm{n}=30+$ neo-XY $(\mathrm{FN}=32)$ in $A$. taitensis. In the case of $A$. shengenae a different chromosome number was reported in a previous paper: $2 \mathrm{n}=26+X 0^{27}$ compared to $2 \mathrm{n}=32+\mathrm{X} 0$ found in the present study. However, since the previous findings were based on a single male only, a mistake cannot be ruled out and it is unclear whether the reported data reflect intraspecific variability or an incorrectly tagged individual. The 33 chromosome set in males is thus probably a plesiomorphic character for both A. kilimandjarica and A. shengenae, since a similar chromosome number is also found in Hexacentrus $^{26}$. The neo-XY sex chromosome system is derived from the X0 system and is rarely observed in tettigoniids. However, two East African Spalacomimus (Hetrodinae) species have revealed divergent origins of this system in studies involving both classical and molecular cytogenetic techniques ${ }^{66}$. Based on C-banding analysis, one may suggest that the neo-XY system arose in A. taitensis (endemic to the Taita Hills in Kenya) due to rearrangements resulting from a tandem fusion between the original acrocentric $\mathrm{X}$ chromosome and part of the medium-sized chromosome pair with thick (double) C-bands near the distal end. The acrocentric neo-Y (a medium-sized member of the set), is partially homologous to the autosome, with a double C-band. In Hexacentrinae, a neo$\mathrm{XY}$ has been found in the Indian species Euhexacentrus annulicornis ${ }^{67}$, but in that case the karyotype had only metacentric chromosomes, including both neo-X and neo- $\mathrm{Y}$ originated by multiple rearrangements. 
In the southern group two species $A$. vociferator and A. megaloptera showed diminished chromosome numbers with $2 \mathrm{n}=28+\mathrm{X} 0(\mathrm{FN}=31)$ and $2 \mathrm{n}=24+$ neo- $\mathrm{X}_{1} \mathrm{X}_{2} \mathrm{Y}(\mathrm{FN}=31)$, respectively. In both species, one Robertsonian (centric) fusion between large/medium-sized autosomes affected the first pair of autosomes (bi-armed chromosomes). The neo- $\mathrm{X}_{1} \mathrm{X}_{2} \mathrm{Y}$ system is very rare in tettigoniids ${ }^{68,69}$. The series of rearrangements giving rise to this multiple sex chromosome system derived directly from the X0 system, and probably occurred in A. vociferator by translocations/and or inversion between the $\mathrm{X}$ chromosome and two pairs of autosomes. To confirm such a mechanism of chromosomal rearrangements in this species it would be necessary to apply markers obtained by silver impregnation and fluorescence in situ hybridization using ribosomal DNA and telomeric DNA.

It should be noted, that upon C-staining, chromosomal regions showed some quantitative and qualitative variation between the analyzed species in terms of constitutive heterochromatin. Characteristics of Aerotegmina species common to the northern and the southern groups were: i) heterochromatin blocks in the paracentromeric region with a thick $\mathrm{C}$-band and a minute telomeric C-band in the $\mathrm{X}$ and/or neo-X chromosomes, and, ii) one medium-sized/small pair was heterochromatinized. This set of similarities in heterochromatin was exclusively found in this monophyletic group of Hexacentrinae.

The role of chromosomal rearrangements (CRs), including the reduced chromosome numbers in the evolution and in originating reproductive barriers has been investigated having a causative role in isolating species or populations in some genera of Hemiptera ${ }^{70,71}$, Hymenoptera: Formicidae ${ }^{72}$, Diptera ${ }^{73}$, Coleoptera ${ }^{74,75}$, Lepidoptera ${ }^{76}$, and Orthoptera ${ }^{77,78}$. To better understand the role of chromosome changes in species diversification interaction between chromosomal and genetic variability requires analysis in the context of species' geographical distribution (e.g. $\left.{ }^{65,70,77,79,80}\right)$.

Considering the current contrasting geographical range and respective karyotypes of Aerotegmina species, the fixation of different CRs either by genetic drift or isolation could have been triggered by recurrent climatic events that continuously changed the environment. The split into two groups would have involved probably dispersion, vicariance (allopatry) and extinction events, geographic speciation via vicariance has been the most documented to date and is a common speciation model across tropical Africa ${ }^{81}$. The geographic isolation of the ancestor of Aerotegmina species due to humid and arid periods (see above) changing their habitat led to a split of the two lineages within the genus (northern small-sized species and southern large-sized species). Chromosomal changes seem to be a consequence of adaptation to different habitats, but mutations (including chromosomal changes) always take place before adaptation. Chromosomal rearrangements could be more or less adaptive depending on affected genes/regions and their interactions. In any case, they represent a very important reproductive barrier themselves and, further, a possible mechanism of speciation.

When mapped on the phylogenetic tree, the observed cytogenetic characteristics reflect the phylogenetic pattern, suggesting that certain cytogenetic character stages, like a lowered number of chromosomes, occur in closely related species. Genetic differentiation and habitat specialization was accompanied by chromosomal variation in Aerotegmina. Additional studies are required focusing on the cytogenetic analysis of more individuals especially of A. vociferator and populations/localities of other species to increase the cytogenetic data on Aerotegmina.

\section{Conclusions}

We found that Aerotegmina species evolved as a result of vicariance, dispersal and extinction events resulting in a clear pattern of body size variation and spatial separation of clades. These events were probably linked to geological processes and past climate changes. Habitat fragmentation within the Eastern Arc Mountain could have boosted allopatric speciation through vicariance in a previously isolated mountain region. Our results support the idea of a montane origin of the genus Aerotegmina dated in the Eocene, although the majority of species-level diversification appears to have taken place from the Pliocene onwards. However, the structure of karyotypes and varying chromosome numbers indicate that Aerotegmina speciation is still an ongoing process. Various processes and mechanisms of speciation are interconnected and are responsible for the patterns of genetic diversity that can be observed at different population and phylogenetic levels in nature.

Received: 28 July 2020; Accepted: 26 April 2021

Published online: 10 May 2021

\section{References}

1. Chapman, C. A. \& Chapman, L. J. Mid-elevation forests: a history of disturbance and regeneration. In East African Ecosystems and their Conservation (eds McClanahan, T. R. \& Young, T. P.) 385-400 (Oxford University Press, 1996).

2. Myers, N., Mittermeier, R. A., Mittermeier, C. G., da Fonseca, G. A. B. \& Kent, J. Biodiversity hotspots for conservation priorities. Nature 403, 853-858 (2000).

3. Brée, B. et al. Diversification of African rainforest restricted clades: Piptostigmateae and Annickieae (Annonaceae). Diversity 12(6), 227 (2020).

4. Couvreur, T. L., Chatrou, L. W., Sosef, M. S. \& Richardson, J. E. Molecular phylogenetics reveal multiple tertiary vicariance origins of the African rain forest trees. BMC Biol. 6, 54 (2008).

5. Ricketts, T. H. et al. Pinpointing and preventing imminent extinctions. Proc. Natl. Acad. Sci. U. S. A. 102, 18497-18501 (2005).

6. Hemp, C. \& Hemp, A. Conservation Status of the Elegant Yellow-Black Bush-cricket (Meruterrana elegans) (Orthoptera: Phaneropterinae) - a critically endangered species on Mt Kenya. J. East Afr. Nat. Hist. 107(1), 9-16 (2018).

7. Hemp, C. \& Heller, K.-G. Orthoptera (Tettigoniidae and Acridoidea) from Miombo woodlands of Central Tanzania with the description of new taxa. Zootaxa 4671(2), 151-194 (2019).

8. Burgess, N. D. \& Clarke, G. P. Coastal Forests of Eastern Africa (IUCN, 2000).

9. Burgess, N. D. et al. The biological importance of the Eastern Arc Mountains of Tanzania and Kenya. Biol. Cons. 134, 209-231 (2007).

10. Hall, J., Burgess, N. D., Lovett, J., Mbilinyi, B. \& Gereau, R. E. Conservation implications of deforestation across an elevational gradient in the Eastern ArcMountains, Tanzania. Biol. Conserv. 142(11), 2510-2521 (2009). 
11. Lovett, J. C. \& Wasser, S. K. Biogeography and Ecology of the Rainforests of Eastern Africa (Cambridge University Press, 1993).

12. Hamilton, A. C. The climate of the East Usambara Mts. In Forest Conservation in the East Usambara Mountains, Tanzania (ed. Hamilton, A. C.) (IUCN, 1989).

13. Trauth, M. H., Larrasoaña, J. C. \& Mudelsee, M. Trends, rhythms and events in Plio-Pleistocene African climate. Quat. Sci. Rev. 28, 399-411 (2009).

14. Hemp, C. et al. The Phlesirtes complex (Orthoptera, Tettigoniidae, Conocephalinae, Conocephalini) reviewed: integrating morphological, molecular, chromosomal, and bioacoustic data. Syst. Entomol. 35, 554-580 (2010).

15. Hemp, C., Heller, K.-G., Warchałowska-Śliwa, E. \& Hemp, A. Lunidia, a new genus of African Phaneropterinae (Orthoptera: Tettigoniidae). Org. Divers. Evol. 10, 215-226 (2010).

16. Hemp, C., Kehl, S., Heller, K.-G., Wägele, J. W. \& Hemp, A. Ecological adaptations of grassland inhabiting flightless Orthoptera: Fulvoscirtes and Acanthoscirtes, two new genera of African Karniellina (Orthoptera, Tettigoniidae, Conocephalinae, Conocephalini). Syst. Entomol. 37, 387-407 (2012).

17. Hemp, C., Heller, K.-G., Warchałowska-Śliwa, E., Grzywacz, B. \& Hemp, A. New genera and new species of Acrometopini (Orthoptera: Tettigonioidea, Phaneropterinae) from East Africa and a review of all known stridulatory organs, songs and karyotypes of the tribe. Insect Syst. Evol. 49, 241-298 (2018).

18. Hemp, C., Kehl, S., Schultz, O., Wägele, W. \& Hemp, A. Climatic fluctuations and topography as motor for speciation: case study on Parepistaurus Karsch, 1896 (Orthoptera: Acrididae, Coptacridinae). Syst. Entomol. 40, 17-34 (2015).

19. Schultz, O., Hemp, C., Hemp, A. \& Wägele, J. W. Molecular phylogeny of the endemic East African flightless grasshoppers Altiusambilla Jago, 1981, Usambilla (Sjöstedt, 1909) and Rhainopomma Jago, 1981 (Orthoptera: Acridoidea). Syst. Entomol. 32, 712-719 (2007).

20. Hemp, C., Scherer, C., Brandl, R. \& Pinkert, S. The origin of the endemic African grasshopper family Lentulidae (Orthoptera: Acridoidea) and its climate-induced diversification. J Biogeogr. 47, 1805-1815 (2020).

21. Nonnotte, P. et al. New K-Ar age determinations of Kilimanjaro volcano in the North Tanzania diverging rift, East Africa. J. Volcanol. Geotherm. Res. 173, 99-112 (2008).

22. Hemp, A. \& Hemp, C. Broken bridges: the isolation of Kilimanjaro’s ecosystem. Glob. Chang. Biol. 24(8), 1-9 (2018).

23. Cigliano, M. M., Braun, H., Eades, D. C. \& Otte, D. Orthoptera Species File. Version 5.0/5.0. [12.12.2020]. http://Orthoptera.Speci esFile.org.

24. Hemp, C. Aerotegmina, a new genus of African Listroscelidinae (Orthoptera: Tettigoniidae, Listroscelidinae, Hexacentrini). J. Orthoptera Res. 10(1), 125-132 (2001).

25. Heller, K.-G. \& Hemp, C. Extremely divergent song types in the genus Aerotegmina Hemp (Orthoptera: Tettigoniidae: Hexacentrinae) and the description of a new species from the Eastern Arc Mountains of Tanzania (East Africa). Bioacoustics 28, 269-285 (2018).

26. Hemp, C. Cloud forests in East Africa as evolutionary motors for speciation processes of flightless Saltatoria species. In Mountains in the Mist: Science for Conservation and Management of Tropical Montane Cloud Forests (Chap. 18: 192-196) (eds Bruijnzeel, A. et al.) (University of Hawaii Press, 2010).

27. Hemp, C., Heller, K.-G., Warchalowska-Sliwa, E. \& Hemp, A. The genus Aerotegmina (Orthoptera, Tettigoniidae, Hexacentrinae): chromosomes, morphological relations, phylogeographical patterns and description of a new species. Org. Divers. Evol. 13, 521-530 (2013).

28. Hemp, C., Grzywacz, B., Warchałowska-Śliwa, E. \& Hemp, A. Topography and climatic fluctuations boosting speciation: biogeography and a molecular phylogeny of the East African genera Afroanthracites Hemp \& Ingrisch and Afroagraecia Ingrisch \& Hemp (Orthoptera, Tettigoniidae, Conocephalinae, Agraeciini). Org. Divers. Evol. 16, 211-223 (2016).

29. Hemp, C., Heller, K.-G., Warchałowska-Śliwa, E. \& Grzywacz, B. A molecular phylogeny of East African Amytta (Orthoptera: Tettigoniidae, Meconematinae) with data on their cytogenetics. Syst. Entomol. 43, 239-249 (2018).

30. Folmer, O., Black, M., Hoeh, W., Lutz, R. \& Vrijenhoek, R. DNA primers for amplification of mitochondrial cytochrome c oxidase subunit I from diverse metazoan invertebrates. Mol. Mar. Biol. Biotechnol. 3(5), 294-299 (1994).

31. Kocher, T. D. et al. Dynamics of mitochondrial evolution in animals: amplification and sequencing with conserved primers. Proc. Natl. Acad. Sci. U. S. A. 86, 6196-6200 (1989).

32. Colgan, D. J. et al. Histone H3 and U2 snRNA DNA sequences and arthropod molecular evolution. Aust. J. Zool. 46, 419-437 (1998).

33. Thompson, J. D. et al. The ClustalX windows interface: flexible strategies for multiple sequence alignment aided by quality analysis tools. Nucl. Acid. Res. 25, 4876-4882 (1997).

34. Kumar, S., Stecher, G., Li, M., Knyaz, C. \& Tamura, K. MEGA X: molecular evolutionary genetics analysis across computing platforms. Mol. Biol. Evol. 35, 1547-1549 (2018).

35. Xia, X. H., Xie, Z., Salemi, M., Chen, L. \& Wang, Y. An index of substitution saturation and its application. Mol. Phylogenet. Evol. 26, 1-7 (2003)

36. Xia, X. DAMBE5: a comprehensive software package for data analysis in molecular biology and evolution. Mol. Biol. Evol. 30, $1720-1728(2013)$.

37. Farris, J. S., Kallersjo, M., Kluge, A. G. \& Bult, C. Constructing a significance test for incongruence. Syst. Biol. 44, 570-572 (1995).

38. Swofford, D. L. PAUP*. Phylogenetic Analysis Using Parsimony ( ${ }^{*}$ and Other Methods) Version 4.0b10a (Sinauer Associates, 2002).

39. Nylander, J. A. A. MrModeltest Vol. 2 (Uppsala University, 2004).

40. Ronquist, F. et al. MrBayes 3.2: efficient Bayesian phylogenetic inference and model choice across a large model space. Syst. Biol. 61, 539-542 (2012).

41. Rambaut, A., Drummond, A. J., Xie, D., Baele, G. \& Suchard, M. A. Posterior summarisation in Bayesian phylogenetics using Tracer 1.7. Syst. Biol. 67(5), 901-904 (2018).

42. Nguyen, L. T., Schmidt, H. A., von Haeseler, A. \& Minh, B. Q. IQ-TREE: a fast and effective stochastic algorithm for estimating maximum likelihood phylogenies. Mol. Biol. Evol. 32, 268-274 (2015).

43. Drummond, A. J., Suchard, M. A., Xie, D. \& Rambaut, A. Bayesian phylogenetics with BEAUti and the BEAST 1.7. Mol. Biol. Evol. 29, 1969-1973 (2012).

44. Mugleston, J. D., Naegle, M., Song, H. \& Whiting, F. A comprehensive phylogeny of Tettigoniidae (Orthoptera: Ensifera) reveals extensive ectomorph convergence and widespread taxonomic incongruence. Insect Syst. Div. 2(4), 1-27 (2018).

45. Yu, Y., Harris, A. J. \& He, X. J. S-DIVA (statistical dispersal-vicariance analysis): a tool for inferring biogeographic histories. Mol. Phylogenet. Evol. 56, 848-850 (2010).

46. Yu, Y., Harris, A. J., Blair, C. \& He, X. J. RASP (Reconstruct Ancestral State in Phylogenies): a tool for historical biogeography. Mol. Phylogenet. Evol. 87, 46-49 (2015).

47. Sumner, A. T. A simple technique for demonstrating centromere heterochromatin. Exp. Cell Res. 75, 304-306 (1972).

48. Revell, L. J. Phytools: an R package for phylogenetic comparative biology (and other things). Methods Ecol. Evol. 3, 217-223 (2012).

49. R Core Team. R: A Language and Environment for Statistical Computing (R Core Team, 2020).

50. Hemp, C. Faunistic relations between the ranges of the Eastern Arc Mountains: relocation of Peronura hildebrandtiana Karsch, 1889 (Tettigoniidae: Phaneropterinae), the description of the male and implications from its phylogeographical pattern. Zootaxa 3006, 63-68 (2011). 
51. Hemp, C., Schultz, O., Hemp, A. \& Wägele, J. W. New Lentulidae species from East Africa (Orthoptera: Saltatoria). J. Orthoptera Res. 16, 85-96 (2007).

52. Hemp, C. \& Kehl, S. Taxonomic changes and new species of the flightless genus Parepistaurus Karsch, 1896 (Orthoptera: Acrididae, Coptacridinae) from mountainous East Africa. J. Orthoptera Res. 19, 31-39 (2010).

53. Hemp, C., Kehl, S., Heller, K.-G., Wägele, J. W. \& Hemp, A. A new genus of African Karniellina (Orthoptera, Tettigoniidae, Conocephalinae, Conocephalini): integrating morphological, molecular, and bioacoustical data. Syst. Entomol. 35, 581-595 (2010).

54. Schultz, O. Molekulare Phylogenie und Radiation endemischer Orthopteren Ostafrikas. M.Sc. thesis, Ruhr-Universitaet, Bochum, Germany (2004).

55. Hemp, C. Aerotegmina shengenae, a new species of Listroscelidinae (Orthoptera: Tettigoniidae) from the Eastern Arc Mountains of East Africa. J. Orthoptera Res. 15, 99-103 (2006).

56. Cigliano, M. M., Braun, H., Eades, D. C. \& Otte, D. Orthoptera Species File. Version 5.0/5.0. [2020]. http://Orthoptera.SpeciesFile. org.

57. Gorochov, A. V. New taxa of the subfamily Meconematinae (Orthoptera: Tettigoniidae) from Africa and adjacent islands. Proc. ZIN RAS 321(1), 32-64 (2017).

58. Axelrod, D. I. \& Raven, P. H. Late Cretaceous and Tertiary vegetation history of Africa. In Biogeography and Ecology of Southern Africa (ed. Werger, M. J. A.) 77-130 (W Junk Bv Publishers, The Hague, 1978).

59. Wasser, S. K. \& Lovett, J. C. Biogeography and Ecology of the Rainforests of Eastern Africa (Cambridge University Press, 1993).

60. Morley, R. J. Origin and Evolution of Tropical Rain Forests (Wiley, 2000).

61. Couvreur, T. L. P., Richardson, J. E., Sosef, M. S. M., Erkens, R. H. J. \& Chatrou, L. W. Evolution of syncarpy and other morphological characters in African Annonaceae: a posterior mapping approach. Mol. Phylogenet. Evol. 47, 302-318 (2008).

62. deMenocal, P. African climate change and faunal evolution during the Pilocene-Pleistocene. Earth Planet. Sci. Lett. 220, 3-24 (2004).

63. Trauth, M. H., Maslin, M. A., Deino, A. \& Strecker, M. R. Late Cenozoic moisture history of East Africa. Science 309(5743), 2051-2053 (2005).

64. Dobigny, G., Aniskin, V. \& Volobouev, V. Explosive chromosome evolution and speciation in the gerbil genus Taterillus (Rodentia, Gerbillinae): a case of two new cryptic species. Cytogenet. Genome Res. 96, 117-124 (2002).

65. Micolino, R., Cristiano, M. P., Travenzoli, N. M., Lopes, D. M. \& Cardoso, D. C. Chromosomal dynamics in space and time: evolutionary history of Mycetophylax ants across past climatic changes in the Brazilian Atlantic coast. Sci. Rep. 9, 18800 (2019).

66. Warchałowska-Śliwa, E., Grzywacz, B., Maryańska-Nadachowska, A., Hemp, A. \& Hemp, C. Different steps in the evolution of neo-sex chromosomes in two East African Spalacomimus species (Orthoptera: Tettigoniidae: Hetrodinae). Eur. J. Entomol. 112(1), $1-10$ (2015).

67. Aswathanarayana, N. V. \& Ashwath, S. K. Karyology of Tettigonids (Class: Insecta). Chromosomes and constitutive heterochromatin in Euhexacentrus annulicornis Stol. Subfam: Listroscelinae. Entomon 10, 97-101 (1985).

68. Warchałowska-Śliwa, E. Karyotype characteristics of katydid orthopterans (Ensifera, Tettigoniidae) and remarks on their evolution at different taxonomic levels. Folia Biol. (Kraków) 46, 143-176 (1998).

69. Warchałowska-Śliwa, E. et al. Changes in the numbers of chromosomes and sex determination system in bushcrickets of the genus Odontura (Orthoptera, Tettigoniidae, Phaneropterinae). Eur. J. Entomol. 108(2), 183-195 (2011).

70. Mills, P. J. \& Cook, L. G. Rapid chromosomal evolution in a morphologically cryptic radiation. Mol. Phylogenet. Evol. 77, 126-135 (2014).

71. Chirino, M. G., Dalíková, M., Marec, F. R. \& Bressa, M. J. Chromosomal distribution of interstitial telomeric sequences as signs of evolution through chromosome fusion in six species of the giant water bugs (Hemiptera, Belostoma). Ecol. Evol. 7, 5227-5235 (2017).

72. Cardoso, D. C., Pompolo, S. G., Cristiano, M. P. \& Tavares, M. G. The role of fusion in ant chromosome evolution: insights from cytogenetic analysis using a molecular phylogenetic approach in the genus Mycetophylax. PLoS ONE 9, e87473 (2014).

73. Coluzzi, M., Sabatini, A., della Torre, A., Di Deco, M. A. \& Petrarca, V. A polytene chromosome analysis of the Anopheles gambiae species complex. Science 298, 1415-1418 (2002).

74. Kobayashi, N. et al. Two cryptic species of the phytophagous ladybird beetle Epilachna vigintioctopunctata (Coleoptera: Coccinellidae) detected by analyses of mitochondrial DNA and karyotypes, and crossing experiments. Zool. Sci. 17, 1159-1166 (2000).

75. Xavier, C., Soares, R. V. S., Amorim, I. C., Cabral-de-Mello, D. C. \& de Moura, R. C. Insights into the karyotype evolution and speciation of the beetle Euchroma gigantea(Coleoptera: Buprestidae). Chromosom. Res. 26, 163-178 (2018).

76. Lucek, K. Evolutionary mechanisms of varying chromosome numbers in the radiation of Erebia butterflies. Genes 9, 166 (2018).

77. Kawakami, T., Butlin, R. K. \& Cooper, S. J. B. Chromosomal speciation revisited: modes of diversification in Australian morabine grasshoppers (Vandiemenella viatica species group). Insects 2, 49-61 (2011).

78. Taffarel, A., Bidau, C. J. \& Marti, D. A. Chromosome fusion polymorphisms in the grasshopper, Dichroplus fuscus (Orthoptera: Acrididae: Melanoplinae): Insights on meiotic effect. Eur. J. Entomol. 112, 11-19 (2015).

79. Fernandes, F. A., Gonçalves, G. L., Ximenes, S. S. F. \& de Freitas, T. R. O. Karyotypic and molecular polymorphisms in Ctenomys torquatus (Rodentia: Ctenomyidae): taxonomic considerations. Genetica 136, 449-459 (2009).

80. Štundlová, J., Šmíd, J., Nguyen, P. \& Štáhlavský, F. Cryptic diversity and dynamic chromosome evolution in Alpine scorpions (Euscorpiidae: Euscorpius). Mol. Phylogenet. Evol. 134, 152-163 (2019).

81. Couvreur, T. L. P. et al. Tectonics, climate and the diversification of the tropical African terrestrial flora and fauna. Biol. Rev. https:// doi.org/10.1111/brv.12644 (2020).

82. QGIS Development Team. QGIS Geographic Information System. Ver. 3.6 Noosa. Open Source Geospatial Foundation Project; http://qgis.osgeo.org (2019).

\section{Acknowledgements}

We are grateful to two anonymous referees for the constructive comments on the manuscript. We thank S. Hugel for valuable discussions and providing specimens of Nepheliphila raptor, Longiphisis sp., and Breviphisis sp. for molecular analyses. We are grateful to the Mauritius and Madagascar authorities for research and export permits ("Project BIOTAS", National Parks and Conservation Service, Republic of Mauritius and N012/18/MEEF/SG/ DGF/DSAP/SCB.RE to S. Hugel). We acknowledge support from the Deutsche Forschungsgemeinschaft (DFG) and express our gratitude to the Tanzania Commission of Science and Technology and the Tanzania Wildlife Research Institute for permitting research (No. 2016-102-ER-96-44). We thank the National Museums of Kenya, Nairobi for continuous support and collaboration. Part of the research received support from the Synthesys Project http://www.synthesys.info/ financed by the European Community Research Infrastructure Action under FP6 "Structuring the European Research Area," which enabled C. Hemp to visit a number of entomological collections in Europe. Last but not least, we would like to thank H. Rowell for suggesting the title of the manuscript. 


\section{Author contributions}

B.G. and C.H. conceived the study; C.H. and K.-G.H. collected the samples; B.G. and M.K. conducted molecular experiments; B.G. analysed the molecular data; E.W.-Ś. conducted and analysed cytogenetic experiments; B.G. wrote the manuscript; all authors read, discussed and approved the final version of the manuscript.

\section{Competing interests}

The authors declare no competing interests.

\section{Additional information}

Supplementary Information The online version contains supplementary material available at https://doi.org/ 10.1038/s41598-021-89364-4.

Correspondence and requests for materials should be addressed to B.G.

Reprints and permissions information is available at www.nature.com/reprints.

Publisher's note Springer Nature remains neutral with regard to jurisdictional claims in published maps and institutional affiliations.

Open Access This article is licensed under a Creative Commons Attribution 4.0 International License, which permits use, sharing, adaptation, distribution and reproduction in any medium or format, as long as you give appropriate credit to the original author(s) and the source, provide a link to the Creative Commons licence, and indicate if changes were made. The images or other third party material in this article are included in the article's Creative Commons licence, unless indicated otherwise in a credit line to the material. If material is not included in the article's Creative Commons licence and your intended use is not permitted by statutory regulation or exceeds the permitted use, you will need to obtain permission directly from the copyright holder. To view a copy of this licence, visit http://creativecommons.org/licenses/by/4.0/.

(C) The Author(s) 2021 